\title{
Antioxidant Capacity and Total Phenolic Content in Honey Brands from Mexican Market and Some Physicochemical Parameters Related
}

\author{
Pedro Mondragón Cortez \\ Department of Food Technology, Center for Research and Assistance in Technology and Design of the State of Jalisco, Zapopan, Mexico
}

\section{Email address:}

pmondragon@ciatej.mx

\section{To cite this article:}

Pedro Mondragón Cortez. Antioxidant Capacity and Total Phenolic Content in Honey Brands from Mexican Market and Some Physicochemical Parameters Related. World Journal of Food Science and Technology. Vol. 3, No. 2, 2019, pp. 20-25.

doi: $10.11648 /$ j.wjfst.20190302.11

Received: May 2, 2019; Accepted: June 12, 2019; Published: June 25, 2019

\begin{abstract}
During the production of a honey brand, artisanal or fresh honey is usually heated and filtered with the purpose of to improve fluency and this way can to facilitate its packaging process. However, an overheated honey can change the original antioxidant capacity, mainly due to the damage that the phenolic compounds have in the honeys. For this reason, the purpose of this work was to determine the behavior of the antioxidant capacity and total phenolic content in twelve samples of honey brand available in the Mexican market. 2, 2-diphenyl-1-picryhydrazyl (DPPH) free radical scavenging activity and total phenolic content were measured. Moreover, moisture, hydroxymethylfurfural (HMF) content, color parameters (L*, $a^{*}$ and $\left.b^{*}\right)$ and fructose and glucose content were also determined by the purpose to support the study of antioxidant capacity in the samples of honey brand studied. The results indicated that honey brands showed an antioxidant capacity in normal levels, in comparison to other types of honey from different countries, despite the fact that the total phenolic content values were relatively low. This behavior observed may be due to the fact that the formation of the compounds with high antioxidant capacity from Maillard reactions, mainly HMF, during the heat of the honeys, which contributed in an important way with the values of the antioxidant capacity observed.
\end{abstract}

Keywords: Antioxidant Capacity, Honey Brand, Overheating, Phenolic Content

\section{Introduction}

Honey is a sweet substance, which is composed mainly of fructose $(38 \%)$, glucose $(31 \%)$, other sugars $(10 \%)$ and water (18\%) [1]. However, honey is rich in minor compounds (around 3\%), which give it remarkable nutritional properties, such as: proteins, enzymes, carotenoids, phenolic compounds, free amino acids, organic acids, vitamins and minerals [2]. For several years, some studies have shown the potential benefit to human health of honeys from different botanical origins, in antimicrobial, anti-inflammatory, antitumor and antioxidant properties [3-6].

The components associated with the antioxidant capacity in honey are mainly phenolic compounds [7, 8]. These compounds are biologically active secondary metabolites from plants, which are transferred to honey by bees that collect nectar from flowers [9].
Therefore, the antioxidant capacity in a honey depends on its floral origin, mainly. However, the processing of honey may also have a negative effect on its antioxidant activity. For example, polyphenol compounds decrease when a food is heated [10]. However, it has been observed that the antioxidant activity in a honey increases during a prolonged heating due to the formation of compounds from Maillard reaction, mainly hydroxymethylfurfural $[11,12]$.

Honey from Mexico enjoys the preference of consumers around of the world due to its good sensory and nutritional properties. Several studies have reported the physicochemical properties and the antioxidant capacity of different types of artisanal or fresh honeys from México [13-16]. In the Mexican market it is also possible to purchase different honey brands, which normally are subject to an industrial 
packaging process that includes heating and filtering. The heating of honey (artisanal or fresh), has two principal purposes during the packaging process: a) destroy microorganisms, and b) dissolve glucose crystals [12, 17]. The dissolution of glucose crystals facilitates the fluidity (reduction of viscosity) of honey and this way is easier to pack. The filtrate removes pollen, bits of wax, and crystals of glucose hydrate. Also, the combination of the heating and filtering process allows for the honey brands to remain on the shelf for several more months without crystallization, which is important because a granulated honey is more likely to ferment than liquid honey. In addition, sensory, speaking, many people prefer a fluid and crystalline honey than a granulated honey.

The purpose of this work was to determine the antioxidant capacity and total phenolic content of twelve honey brands acquired in the supermarket (Guadalajara City, Mexico) and to correlate it with some physicochemical parameters that help to the interpretation, such as color determination $\left(\mathrm{L}^{*}, \mathrm{a}^{*}\right.$ and $\left.b^{*}\right)$, fructose and glucose content, water content and HMF content.

\section{Materials and Methods}

\subsection{Samples of Honey Brands}

Twelve samples of honey brands were purchased in supermarkets in Mexico (Guadalajara) during the month of October 2017, which were identified as H1, H2...H12. All the samples of honey presented their own brand.

\subsection{Determination of Total Antioxidant Capacity}

The method of scavenging activity against 2, 2-diphenyl-1picrylhydrazyl (DPPH) radical of honey was used to determine the total antoxidant capacity [12]. For the preparation of honey samples, $2 \mathrm{~g}$ of each honey was dissolved in $10 \mathrm{ml}$ of distilled water, and then the sample was centrifuged and filtered, respectively. And later, $0.75 \mathrm{~mL}$ of the solution was mixed with $2 \mathrm{~mL}$ of $0.1 \mathrm{mM}$ methanol solution of DPPH. Distilled water was used as a control. After incubation for $60 \mathrm{~min}$ at a room temperature in the dark, the absorbance of the honey solution was measured at $517 \mathrm{~nm}$ against methanol as blank, using a UV-vis spectrophotometer Cintra 6 (GBS Scientific Equipment, Victoria, Australia). The antioxidant activity was expressed as a percentage of inhibition of DPPH radical $\left(\mathrm{AA}_{\mathrm{DPPH}}, \%\right)$ and was calculated by the following equation:

$$
\mathrm{AA}_{\mathrm{DPPH}}(\%)=\left[\left(\mathrm{Ab}_{\text {control }}-\mathrm{Ab}_{\text {honey sample }}\right) / \mathrm{Ab}_{\text {control }}\right] \times 100
$$

\subsection{Determination of Total Phenolic Content}

The total phenolic content of honeys was measured using the Folin-Ciocalteu method [18]. Honey solutions with the concentration of $1 \mathrm{~g} / 10 \mathrm{ml}$ were centrifuged and filtered by a paper filter. Afterwards, $0.5 \mathrm{~mL}$ of the resultant solution were mixed with $2.5 \mathrm{ml}$ of $0.2 \mathrm{~mol} / 1$ solution of Folin Ciocalteu reagent and $2 \mathrm{ml}$ of sodium carbonate solution $(75 \mathrm{~g} / \mathrm{l})$ was added. After incubation in dark and at room temperature for $2 \mathrm{~h}$, absorbance of the reaction mixture was measured at 760 $\mathrm{nm}$ using a UV-Vis spectrophotometer Cintra 6 (GBS Scientific Equipment, Victoria, Australia). The standard curve was produced for gallic acid within the concentration range from 0 to $200 \mathrm{mg} / \mathrm{l}$. The total phenolic content was expressed as gallic acid equivalents in $\mathrm{mg} / 100 \mathrm{~g}$ of honey sample (mgGAE/100 g).

\subsection{Physicochemical Analysis}

The moisture of the honey was determined using the refractive index at $20^{\circ} \mathrm{C}$ and was measured with a $\mathrm{ABBE}$ refractometer (Japan). The results were expressed as the percentage of moisture.

Color parameters $\left(\mathrm{L}^{*}, \mathrm{a}^{*}, \mathrm{~b}^{*}\right)$ were established in the CIE system using a Minolta CM-5 Chroma-meter (KonicaMinolta, Japan) with illuminant $\mathrm{D}_{65}$ under an observed angle of $10^{\circ}$. About $40 \mathrm{~g}$ honey samples was weighed into glass petri dish (30 $\mathrm{mm}$ in diameter) for color determination. The instrument was calibrated with a white background.

Hydroxymethylfurfural (HMF) content was determined according to a spectrophotometric method [19], using a UVVis spectrophotometer Cintra 6 (GBS Scientific Equipment, Victoria, Australia). Results were expressed in HMF $\mathrm{mg} / \mathrm{kg}$ of honey.

\subsection{Sugars Analysis}

The fructose and glucose content were assessed using a HPLC method [20]. The chromatographic mobile phase consisted of a mixture of water-acetonitrile (25-75), the flow was kept constant at $1 \mathrm{ml} / \mathrm{min}$. The HPLC equipment comprised a binary pump, an auto-sampler, and a refractive index detector, all from Varian Prostar (Varian Inc., Palo Alto, CA, USA). Separation was performed on a $5 \mu \mathrm{m} \mathrm{LC}-$ $\mathrm{NH}_{2}$ column of $250 \mathrm{~mm}$ x $4.6 \mathrm{~mm}$ (Supelco, Bellefonte, PA, USA).

\subsection{Statistical Analysis}

All analyzes were carried out in triplicate and the data were expressed as means + standard deviations (SD), which were calculated using Excel (Microsoft Office, Version 2016).

\section{Results and Discussion}

\subsection{Physicochemical Parameters of Honey Brand: Effect of the Overheating}

Table 1 shows the visual characteristics of the honey samples, as well as the information declared on the packaging label. All the honey brands visually showed no signs of crystallization. All honey brands presented a dark color. On the packaging label, the manufacturer declared a purity of $100 \%$ for all honeys used in this work, with the exception of two samples (H6 and H10). The expiration date declared on the packaging of honey brands was indicated in a range between August 2019 and January 2020. 
Table 1. Visual characteristics and information declared on the label of the honey brands purchased.

\begin{tabular}{lllll}
\hline Honey & Visual color & Consistency & Purity declared & Expiration date \\
\hline H1 & Dark & Fluid & $100 \%$ & August 2019 \\
H2 & Dark & Fluid & $100 \%$ & January 2020 \\
H3 & Dark & Fluid & $100 \%$ & September 2019 \\
H4 & Dark & Fluid & $100 \%$ & December 2019 \\
H5 & Dark & Fluid & $100 \%$ & February 2020 \\
H6 & Dark & Fluid & N/A & November 2019 \\
H7 & Dark & Fluid & $100 \%$ & February 2020 \\
H8 & Dark & Fluid & $100 \%$ & January 2020 \\
H9 & Dark & Fluid & $100 \%$ & January 2020 \\
H10 & Dark & Fluid & N/A & October 2019 \\
H11 & Dark & Fluid & $100 \%$ & September 2019 \\
H12 & Dark & Fluid & $100 \%$ & September 2019 \\
\hline
\end{tabular}

Information not available (N/A)

In this work, we hypothesized that the honey brands were subjected to an overheated, therefore the dark color that they presented was due, at least in part, to chemical changes, mainly non-enzymatic darkening reactions, for example the Maillard reactions during the overheating. Honey color is the most important sensory property perceived by the consumers, for this reason was investigated in this work. Table 2 shows the values of the color parameters $\left(\mathrm{L}^{*}, \mathrm{a}^{*}\right.$ and $\left.\mathrm{b}^{*}\right)$ found in the samples of honey brand. The $\mathrm{L}^{*}$ values varied from 23.89 to 44.52. And according to the following classification, where a value of $L^{*}>50$ indicates a clear honey and a value of $\mathrm{L}^{*}<50$ indicates a dark honey [21], the honey brands analyzed can be classified as dark honeys, since the $\mathrm{L}^{*}$ value in the honey brands found is well below the value of 50 . Therefore, it is possible to assume that the darken of the honey brands in part was due to Maillard reactions. The a* value varied from 1.26 to 9.10 and the $b^{*}$ values was founded between 5.19 and 19.05 .

Table 2. Color parameters of honey brands.

\begin{tabular}{llll}
\hline Honey & L* & $\mathbf{a}^{*}$ & $\mathbf{b}^{*}$ \\
\hline H1 & $28.68 \pm 0.97$ & $2.65 \pm 0.74$ & $12.94 \pm 0.51$ \\
H2 & $23.89 \pm 0.87$ & $8.83 \pm 0.50$ & $6.89 \pm 0.66$ \\
H3 & $40.79 \pm 0.83$ & $5.07 \pm 0.25$ & $5.15 \pm 0.68$ \\
H4 & $38.22 \pm 0.40$ & $1.95 \pm 0.26$ & $7.06 \pm 0.63$ \\
H5 & $43.45 \pm 1.28$ & $6.47 \pm 0.70$ & $19.05 \pm 0.67$ \\
H6 & $34.26 \pm 0.39$ & $3.69 \pm 0.39$ & $15.88 \pm 0.90$ \\
H7 & $32.13 \pm 0.59$ & $1.26 \pm 0.33$ & $8.49 \pm 0.74$ \\
H8 & $42.20 \pm 0.92$ & $4.76 \pm 0.50$ & $11.25 \pm 0.30$ \\
H9 & $44.52 \pm 0.52$ & $9.10 \pm 0.51$ & $17.67 \pm 0.53$ \\
H10 & $33.19 \pm 0.39$ & $3.03 \pm 0.55$ & $18.17 \pm 0.25$ \\
H11 & $41.55 \pm 0.40$ & $4.44 \pm 0.28$ & $11.42 \pm 0.29$ \\
H12 & $41.65 \pm 1.05$ & $3.53 \pm 0.37$ & $13.67 \pm 0.54$ \\
\hline
\end{tabular}

Results are expressed as mean values \pm standard deviation

Table 3. Physicochemical parameters of honey brands.

\begin{tabular}{lllll}
\hline Honey & Water $(\%)$ & HMF content $(\mathbf{m g} / \mathbf{k g})$ & Fructose $(\%)$ & Glucose $(\%)$ \\
\hline H1 & $16.43 \pm 0.23$ & $71.49 \pm 1.23$ & $36.31 \pm 1.19$ & $31.51 \pm 0.50$ \\
H2 & $17.30 \pm 0.20$ & $76.94 \pm 2.06$ & $36.62 \pm 0.52$ & $30.46 \pm 0.35$ \\
H3 & $16.56 \pm 0.11$ & $55.06 \pm 0.36$ & $37.59 \pm 0.49$ & $29.14 \pm 0.39$ \\
H4 & $16.46 \pm 0.11$ & $58.67 \pm 0.69$ & $38.17 \pm 0.60$ & $30.75 \pm 0.32$ \\
H5 & $16.80 \pm 0.10$ & $41.48 \pm 1.33$ & $37.13 \pm 0.86$ & $30.60 \pm 0.38$ \\
H6 & $17.20 \pm 0.17$ & $62.83 \pm 0.90$ & $36.53 \pm 0.53$ & $29.30 \pm 0.31$ \\
H7 & $17.23 \pm 0.15$ & $65.20 \pm 1.30$ & $35.72 \pm 0.52$ & $30.58 \pm 0.79$ \\
H8 & $17.30 \pm 0.26$ & $48.35 \pm 0.65$ & $34.33 \pm 0.23$ & $31.47 \pm 0.48$ \\
H9 & $16.60 \pm 0.10$ & $37.67 \pm 1.64$ & $36.68 \pm 0.68$ & $29.26 \pm 0.36$ \\
H10 & $16.40 \pm 0.10$ & $62.59 \pm 1.27$ & $35.81 \pm 0.70$ & $30.92 \pm 0.89$ \\
H11 & $17.23 \pm 0.05$ & $50.21 \pm 1.47$ & $34.51 \pm 0.21$ & 68.92 \\
H12 & $17.16 \pm 0.20$ & $41.80 \pm 1.50$ & $34.32 \pm 0.78$ & 65.73 \\
\hline
\end{tabular}

Results are expressed as mean values \pm standard deviation

Table 3 illustrates the results obtained of moisture content, HMF content, and sugar composition (fructose and glucose). The HMF content in a honey is an indicator of its freshness, because this compound is not present in fresh honey. However, HMF can be formed into a honey when it remains in inadequate conditions of humidity and temperature during prolonged storage times or when honey is subjected to overheating. In previous studies it has been found that the formation of $\mathrm{HMF}$ increases rapidly when fresh honey is heated at high temperature $\left(>100^{\circ} \mathrm{C}\right)$ in short periods of time $[22,23]$, such as might occur in the industrial packaging of honey. According to international regulations, HMF content should not exceed $40 \mathrm{mg} / \mathrm{kg}$ in honey samples [24, 25]. In this work, all the HMF values founded in the samples of honey brands exceeded the maximum allowed limit, with the exception of one sample, which presented a value of 37 $\mathrm{mg} / \mathrm{kg}$. Samples of honey brands that exceeded the maximum allowed limit of HMF content was found between 41.48 and $76.94 \mathrm{mg} / \mathrm{kg}$. The results suggest that these honey brands were subjected to overheating during the packaging process.

In a honey, a thermal treatment favors the formation of $\mathrm{HMF}$ at the expense of a decrease in the sugar contents, mainly fructose [26]. In this work, the content of fructose and glucose were in the range between 34.32 and $38.17 \%$ and 29.14 and $31.76 \%$, respectively. The sum of fructose and glucose showed values above the minimum level recommended by international standards (65\%) [27]. Presumably, in a fresh honey before being overheated must have higher fructose content than that found in the honey heated, due to the formation of HMF to the expense of the fructose. But, apparently, this relative decrease maintained acceptable levels of fructose content in all the samples of honey brands evaluated. For example, it has been reported an increase of HMF content from 2.04 to $6.13 \mathrm{mg} / \mathrm{kg}$ in honey from Poland 
heated in a water bath $\left(\sim 90^{\circ} \mathrm{C}\right)$ for 60 minutes, observing a decrease in the fructose content about $1.83 \%$ [28]. In addition, the results obtained from fructose content are similar to those found in fresh honey from different latitudes [14, 29].

The water content value in a honey brand can be affected, due to the evaporation of the water in the original honey, when it is subjected to excessive heating. In this work, the water content varied between 16.4 and $17.3 \%$. The water content in the samples of honey brands is within the maximum limit allowed by international regulations $(<20 \%)$. But it is possible to infer that the water content in the honeys prior to heating has been higher than that determined in the samples of honey brand.

\subsection{Total Phenolic Content and Antioxidant Capacity}

In a honey, the main compounds that contribute to the antioxidant activity are phenolic acids, flavonoids, glucose oxidase, catalase, ascorbic acid, protein and carotenoids. Some authors have found a correlation between phenolic compounds and antioxidant capacity in different types of honey [7, 8]. However, it is known that phenolic compounds are susceptible to degradation with temperature. For example, in honey samples of various floral origins subjected to heat treatment $\left(90^{\circ} \mathrm{C} / 5 \mathrm{~min}\right)$ the total phenolic content decreased by about $20 \%$ in honey of lychee flowers [23]. Figure 1 shows the values of the total phenolic contents determined in the samples of honey brands studied. The values varied in a range between 15.29 and $32.18 \mathrm{mg}$ GAE/100 g. These values can be considered relatively low in relation to values obtained in fresh honey from different parts of the world. For example, values between 32.17 and $119.42 \mathrm{mg}$ GAE/100 $\mathrm{g}$ for honeys from Tunisia [30], $54.30 \mathrm{mg}$ GAE/100 $\mathrm{g}$ for Cuban polyfloral honeys [31], and in honeys from Brazil values between 26.0 and $100 \mathrm{mg} \mathrm{GAE} / 100 \mathrm{~g}$ [32]. In other studies, have found values similar to those found in this work. For example, it has been reported values between 16.5 and $133.3 \mathrm{mg} \mathrm{GAE} / 100 \mathrm{~g}$ for honeys from Sicilian (Italy) [33], and in honeys from Turkey values between 16.02 and $120.04 \mathrm{mg} \mathrm{GAE} / 100 \mathrm{~g}$ were found [4]. Therefore, it is possible to infer that the loss of phenolic compounds occurs during the overheating in the packaging process of the honey brands.

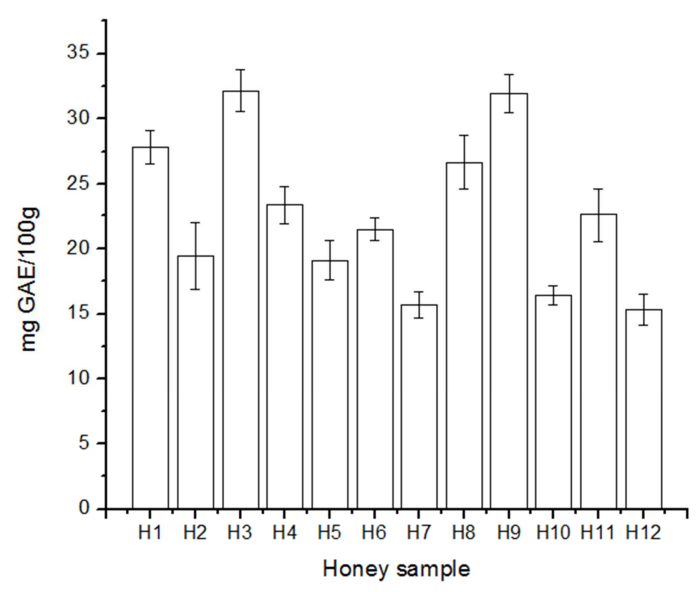

Figure 1. Total phenolic content of honey brands.
On the other hands, the antioxidant capacity of honeys has been determined often using the DPPH method. The DPPH assay measures the ability of the sample to donate hydrogen to the DPPH radical, which results in a quantitative discoloration of the DPPH reagent, which is related to the antioxidant activity. In this work, the DPPH values varied from 30.58 to $51.91 \%$ of in the samples of honey brand analyzed as can be observed in Figure 2. In theory, these values of antioxidant capacity found in honey brands are not influenced totally by the amount of phenolic compounds that still remain in the honey samples after the potential overheating to which they were subjected, but a large percentage of the DPPH value is influenced by the amount of compounds from the Maillard reactions. For example, it has been observed that the antioxidant activity (DPPH) in a honey grew linearly with the increase of the heating time at 50 and $60^{\circ} \mathrm{C}$ [12]. Also, when the temperature was $70^{\circ} \mathrm{C}$, the antioxidant capacity showed a logarithmic growth as function of time. On the other hand, the antioxidant capacity (\% DPPH) increased by around 10 and $12 \%$ in honeys from longan flower and wildflower, respectively, when these samples were heated at $90^{\circ} \mathrm{C} / 5 \mathrm{~min}$ [23]. In other researches, higher DPPH values have been reported, but in fresh honeys from different parts of the world. For example, an average value of $66.8 \%$ inhibition for honey from the north-west Spain from Castanea sativa was observed [34] and in honeys from Portugal values between 106.67 and $168.94 \%$ [7]. However, some samples of fresh honey have similar levels of antioxidant capacity to the values found in this work. For example, it has been reported values between 33.4 and $85.5 \%$ for honeys from Tabasco (México) [16] and in honeys from Lithuania values between 31.1 and $86.9 \%$ in DPPH reaction system [35].

The formation of compounds via the Maillard reactions during the heating of a honey increases its antioxidant capacity, but it must take into consideration the levels that are reached, because of what is still a subject of controversy the health damage that can occur. Therefore, in the packaging process of a honey brand, a balance must be considered between the benefits and potentially damages that can be generated. For example, the use of less severe temperatures and duration times during the packaging process of honey.

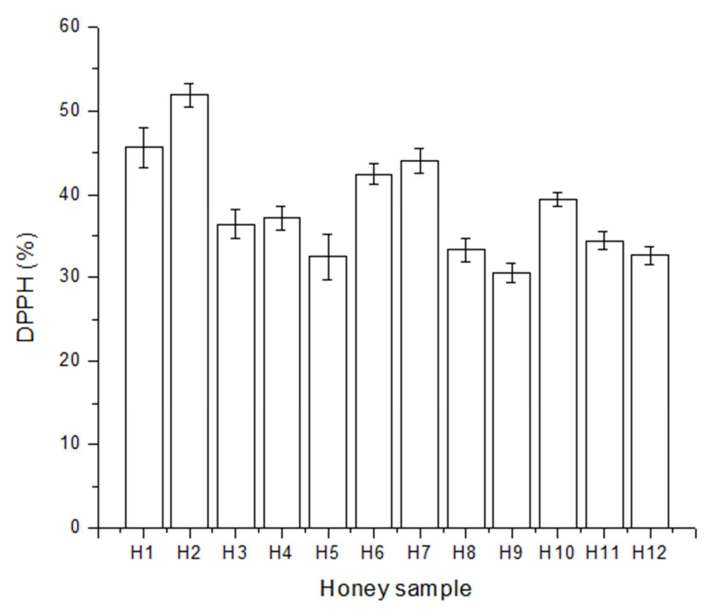

Figure 2. Antioxidant capacity (\% DPPH) of honey brands. 


\section{Conclusion}

HMF content in twelve samples of honey brand showed higher values, which exceeded the limits established in international standards $(<40 \mathrm{mg} / \mathrm{kg})$. Only one sample showed a value recommended by international regulation $(37.67 \mathrm{mg} / \mathrm{kg})$. This behaviour observed was due to an overheating in the honeys, presumably during its packaging process.

The Mexican honey brands had a good level of antioxidant capacity, according to values founded in honey samples (artisanal or fresh) from other countries. However, the antioxidant capacity values in the honey brands found could be highly influenced by the formation of HMF via Maillard reaction produced by overheating during the packaging process. Total phenolic content values in the honey brands were relatively low due to its destruction during the overheated carried out.

Water and sugar content can be considered as good values, despite potential changes suffered during the overheating of the samples, for example water evaporation and fructose transformation to HMF. According to $\mathrm{L}^{*}$ value measured the samples of honey brand are dark. Potentially, this color characteristic in the samples were due to several nonenzymatic darker reactions (Maillard reactions) produced during the packaging process.

\section{References}

[1] Bogdanov, S. and Haldimann, M. (2006). Minerals in honey: Environmental, geographical and botanical aspects. Journal of Apicultural and Research, 46, 269-275.

[2] Da Silva, P. M, Gauche, C, Gonzaga, L. V., Costa, A, C. O. and Fett, R. (2016). Honey: Chemical composition, stability and authenticity. Food Chemistry, 196, 309-323.

[3] Deng, J, Liu, R, Lu, Q, Hao, P, Xu, A, Zhang, J. and Tan, J. (2018). Biochemical properties, antibacterial and cellular antioxidant activities of buckwheat honey in comparison to manuka honey. Food Chemistry, 252, 243-249.

[4] Can, Z, Oktay, Y, Sahin, H, Turumtay, E. A, Silic, S. and Kolayli, S. (2015). An investigation of Turkish honeys: Their physicochemical properties, antioxidant capacities and phenolic profiles. Food Chemistry 180, 133-141.

[5] Escuredo, O, Míguez, M, Fernández-González, M. and Seijo, M, C. (2013). Nutritional value and antioxidant activity of honeys produced in a European Atlantic area. Food Chemistry, 138, 851-856.

[6] Isla, M, I, Craig, A, Ordoñez, R, Zampini, C, Sayago, J, Bedascarrasbure, E, Alvarez, A, Salomón, V. and Maldonado, L. (2011). Physico chemical and bioactive properties of honeys from Northwestern Argentina. LWT-Food Science and Technology, 44, 1922-1930.

[7] Ferreira, I. C. F. R, Aires, E, Barreira J. C. M. and Estevinho, L, M. (2009). Antioxidant activity of Portuguese honey samples: different contributions of the entire honey and phenolic extract. Food Chemistry, 114, 1438-1443.
[8] Bertoncelj, J, Doberšek, U, Jamnik, M. and Golob, T. (2007). Evaluation of the phenolic content, antioxidant activity and colour of Slovenian honey. Food Chemistry, 105, 822-828.

[9] Al-Mamary, M, Al-Meeri, A. and Al-Habori, M. (2002). Antioxidant activities and total phenolic of different types of honey. Nutrition Research 22, 1041-1047.

[10] Kalt, W, Howell, A, Duy, J. C, Forney, C. F. and McDonald, J. E. (2001). Horticultural factors affecting antioxidant capacity of blueberries and other small fruit. Horticulture Technology, 11, 523-528.

[11] Tosi, E. A, Ciappini, M, Re, E. and Lucero, H. (2002). Honey thermal treatment effect on hydroxymethylfurfural content. Food Chemistry, 77, 71-74.

[12] Turkmen, N, Sari, F, Poyrazoglu, E. S. and Velioglu, Y. S. (2006). Effects of prolonged heating on antioxidant activity and color of honey. Food Chemistry, 95, 653-657.

[13] Quintero-Lira, A, Ángeles-Santos, A, Aguirre-Álvarez, G, Reyes-Munguía, A., Almaraz-Buendía, I and Campos-Montiel R. G. (2017). Effects of liquefying crystallized honey by ultrasound on crystal size, 5-hydroxymethylfurfural, colour, phenolic compounds and antioxidant activity. European Food Research and Technology, 243, 619-626.

[14] Mondragón Cortez, P, Ulloa, J. A, Rosas Ulloa, P, Rodríguez, R. and Reséndiz Vázquez, J. A. (2013). Physicochemical characterization of honey from the West region of México. CYTA-Journal of Food, 11, 7-13.

[15] Rodríguez, B. A, Mendoza, S, Iturriaga, M. H and CatañoTostado, E. (2012). Quality parameters and antioxidant and antibacterial properties of some Mexican honeys. Journal of Food Science, 71, C121-C127.

[16] Ruiz-Navajas, Y, Viuda-Martos, M, Fernández-López, J, Zaldívar-Cruz, J. M, Kuri, V. and Pérez-Álvarez, J. A. (2011). Antioxidant Activity of Artisanal Honey from Tabasco, Mexico. International Journal of Food Properties, 14, 459-470.

[17] Turhan, I, Tetik, N, Karhan, M, Gurel, F. and Reyhan Tavukcuoglu, H. (2008). Quality of honeys influenced by thermal treatment. LWT-Food Science and Technology, 41 (8), 1396-1399.

[18] Meda, A, Lamien, C. E, Romito, M, Millogo, J. and Nacoulma, O. G. (2005) Determination of the Total Phenolic, Flavonoid and Proline Contents in Burkina Fasan Honey, as Well as Their Radical Scavenging Activity. Food Chemistry, 91, 571-577.

[19] Zappala, M, Fallico, B, Arena, E. and Verzera, A. (2005). Methods for the determination of HMF in honey: a comparison. Food Control, 16, 273-277.

[20] Association of Official Analytical Chemists. (1990). Methods of analysis. Washington, D. C. AOAC.

[21] González-Miret, M. L, Terrab, A, Hernanz, D, FernándezRecamales, M. A. and Heredia, F. J. (2005). Multivariate correlation between color and mineral composition of honeys and by theirs botanical origin. Journal of the Agricultural and Food Chemistry, 53, 2574-2580.

[22] Grainger, M. N. C, Owens, A, Manley-Harris, M, Lane, J. R. and Field, R. J. (2017). Kinetics of conversion of dihydroxyacetone to methylglyoxal in New Zealand manuka honey: Part IV Formation of HMF. Food Chemistry, 232, 648-655. 
[23] Chaikham, P, Kemsawasd, V and Apichartsrangkoon, A. (2016). Effects of conventional and ultrasound treatments on physicochemical properties and antioxidant capacity of floral honeys from Northern Thailand. Food Bioscience 15, 19-26.

[24] Codex Alimentarius. (2001). Commission standards. Standards for honey, CODEX STAN 12-1981 Rev. 2 (2001).

[25] European Union. (2002). European Union Directive, Council Directive 2001/110/EC relating to Honey.

[26] Zhao, H, Cheng, N, Zhang, Y, Sun, Z, Zhou, W, Wang, Y. and Cao, W. (2018). The effects of different thermal treatments on amino acid contents and chemometric-based identification of overheated honey. LWT-Food Science and Technology, 96, 133-139.

[27] Codex Honey Standards. (1986). Proposed draft codex standard for honey. A comprehensive survey (C. P. Erridge, Ed.). Ottawa, ON, Canada.

[28] Kowalski, S. (2013). Changes of antioxidant activity and formation of 5-hydroxymethylfurfural in honey during thermal and microwave processing. Food Chemistry, 141, 1378-1382.

[29] Tewari, J and Irudayaraj, J. (2004). Quantification of saccharides in multiple floral honeys using Fourier transform infrared microattenuated total reflectance spectroscopy. Journal of Agriculture and Food Chemistry, 52, 3237-3243.

[30] Boussaid, A, Chouaibi, M, Rezig, L, Hellal, R, Donsi, F, Ferrari, G and Hamdi, S. (2018). Physicochemical and bioactive properties of six honey samples from various floral origins from Tunisia. Arabian Journal of Chemistry, 11, 265274.

[31] Alvarez-Suarez, J. M, Giampieri, F, Brenciani, A, Mazzoni, L, Gasparrini, M, Gonzalez-Paramás, A. M, Santos-Buelga, C, Morroni, G, Simoni, S, Forbes-Hernández, T. Y, Afrin, S, Giovanetti, E. and Battino, M. (2018). Apis mellifera vs Melipona beecheii Cuban polifloral honeys: A comparison based on their physicochemical parameters, chemical composition and biological properties. LWT-Food Science and Technology, 87, 272-279.

[32] Souza do Nascimento, K, Gasparotto Sattler, J. A, Lauer Macedo, L. F, Serna González, C. V, Pereira de Melo, I. L, da Silva Araújo, E, Granato, D, Sattler. and Bicudo de AlmeidaMuradian, L. (2018). Phenolic compounds, antioxidant capacity and physicochemical properties of Brazilian Apis mellifera honeys. LWT-Food Science and Technology, 91, 8594.

[33] Attanzio, A, Tesoriere, L, Allegra, M. and Livrea, M. A. (2016). Monofloral honeys by Sicilian black honeybee (Apis mellifera ssp. sicula) have high reducing power and antioxidant capacity. Food Science 2, 2016.

[34] Rodríguez Flores, S, Escudero, O. and Seijo, M. C. (2016). Characterization and antioxidant capacity of sweet chestnut honey produced in north-west Spain. Journal of Apicultural Science, 60, 19-30.

[35] Baltrusaityte, V. and Venskutonis, P. R. and Ceksteryte, V. (2007). Radical scavenging activity of different floral origin honey and beebread phenolic extracts. Food Chemistry, 101, 502-514. 